\title{
Analysis of wave propagation for wireless implantable body area network application
}

\author{
N. H. Ramli ${ }^{1}$, Haryati Jaafar ${ }^{2}$, Y. S. Lee ${ }^{3}$, Hazila Othman ${ }^{4}$ \\ ${ }^{1,3,4}$ Department of Electronic Engineering Technology, Faculty of Electrical Engineering Technology, \\ Universiti Malaysia Perlis, Malaysia \\ ${ }^{2}$ Department of Electrical Engineering Technology, Faculty of Electrical Engineering Technology, \\ Universiti Malaysia Perlis, Malaysia
}

\begin{tabular}{|c|c|}
\hline Article Info & ABSTRACT \\
\hline Article history: & The enhancement technologies of wireless body area network improved the \\
\hline Received Sep 15, 2018 & $\begin{array}{l}\text { health monitoring system. Previous work have been designed the implantable } \\
\text { chip printed antenna at } 4.8 \mathrm{GHz} \text {. This paper is continuing the investigation }\end{array}$ \\
\hline Revised Dec 1, 2018 & where the antenna wave propagation in term of attenuation and polarization \\
\hline Accepted Jan 22, 2019 & $\begin{array}{l}\text { were studied. The antenna is implanted in human hand voxel model from } \\
\text { CST Microwave Studio Software. The performances of the antenna are }\end{array}$ \\
\hline Keywords: & $\begin{array}{l}\text { evaluated in term of return loss, gain and efficiency. Results show that the } \\
\text { rate attenuation for the propagation is approximately } 0.16 \mathrm{~dB} \text { up to } 0.42 \mathrm{~dB} \text {. }\end{array}$ \\
\hline $\begin{array}{l}\text { Human voxel model } \\
\text { Small implantable antenna }\end{array}$ & $\begin{array}{l}\text { All the results will be guidelines in designing implantable antennas in } \\
\text { futures. }\end{array}$ \\
\hline
\end{tabular}

Wave propagation

Wireless body area network

Copyright () 2019 Institute of Advanced Engineering and Science. All rights reserved.

\section{Corresponding Author:}

Nur Hidayah Binti Ramli,

Department of Electronic Engineering Technology,

Faculty of Engineering Technology,

Universiti Malaysia Perlis.

Email: hidayahramli@unimap.edu.my

\section{INTRODUCTION}

Nowadays, the investigation of the implantable device has been attracting a much attention for researchers due to their applicability particularly for medical sector [1-6]. The patient's vital signs can be monitor in real time via wireless networks through in-body. Others, it can be a part of surgery procedure and effect of drug therapy. The implantable device is also suitable to apply in military sector. The condition and location of the soldier can be detected precisely.

However, there are challenging to design implantable antenna compared to antenna in free space environment [7-10]. The efficiency of the antenna is reduced due to the effect of very strong multipath losses as implanted in human body. Since in the human body has different tissues and organ, there are difficult for signal to propagate. Attenuation occurs due to the weakly conducting tissue and reflection at each of the boundaries of dissimilar tissue. Moreover, there is necessity for implantable antenna to have small size and low power consumption for human safety.

Earlier work has been published in [11-12] where the size of the antenna design is $5 \mathrm{~mm}$ and able to operate at $4.8 \mathrm{GHz}$. The antenna performances are studied in three environments which are in homogenous layer, non-homogeneous layer (skin, fat and muscle) and the real human hand voxel model .The effects of antenna performances are studied in term of gain, efficiency, return loss and radiation pattern. Slot technique is used to reduce the antenna size. Results proved that the antenna is reliable to use for wireless body area network. 
This paper continues the previous work where the wave propagation of the implantable antenna has been evaluated in term of attenuation and polarization. The main purposed of evaluating the antenna polarization is to determine the quality of wave propagation for several angles around the antenna implanted in the human hand model.

\section{THE ANTENNA CONFIGURATIONS}

The implantable printed folded (IPF) antenna design and performances has been published in [11-12]. The antenna is comprised by a single metallic layer which known as copper. The copper has 0.036 $\mathrm{mm}$ thickness and it is printed on both side surfaces of the substrate. The FR4 material is chosen as a substrates which has $\varepsilon_{\mathrm{r}}=4.7$ with loss tangent 0.019 and $1.6 \mathrm{~mm}$ thickness. The optimum configuration of the proposed antenna is illustrated in Figure 1. Commonly, the antenna has a size in $5 \mathrm{~mm} \times 5 \mathrm{~mm} \times 1.6 \mathrm{~mm}$ dimension. There are several radiating element in the antenna design which composed of rectangular shape with multiple E-slots at the center and feeding line. The radiator is center fed by microstrip line with $4.1 \mathrm{~mm}$ length and $3 \mathrm{~mm}$ width. The optimized dimensions of the antenna are: $a=5 \mathrm{~mm}, b=5 \mathrm{~mm}, c=0.8 \mathrm{~mm}, d=$ $0.8 \mathrm{~mm}, e=0.5 \mathrm{~mm}, f=0.7 \mathrm{~mm}$ and $g=4.5 \mathrm{~mm}$.

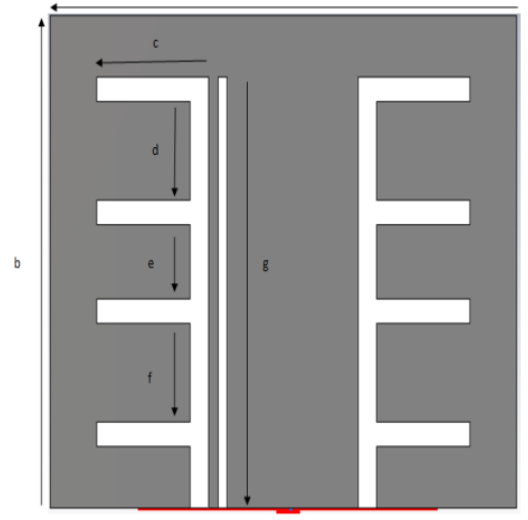

(a)

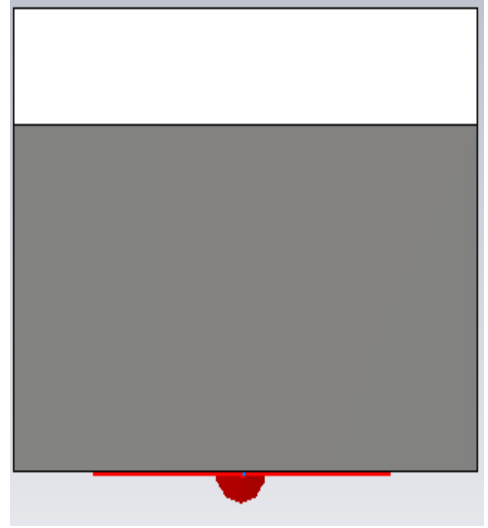

(b)

Figure 1. Geometry of the simulated proposed antenna (a) front view (b) back view

While designing the antenna, some techniques are applied to reduce the size where the slots are added in radiating element, and then the antenna design is folded. There is no ground pin is added as the antenna is too small to create a hole.

\section{INVESTIGATION OF WAVE PROPAGATION IN TERM OF RATE ATTENUATION}

Since the bodies have a variety of tissue and organs, the body needs to be characterized as a medium for wave to propagate in order to create a reliable wireless communication link from and to the human body. The main objective of this investigation is to study the radiation characteristic of both printed monopole antenna and printed loop antenna for wireless implantable body area network applications. The antenna is submerged into human hand voxel model. Another antenna is in free space environment. The wave propagation from the submerged antenna onto the free-air surface can be characterized in term of RF transmission attenuation, $\mathrm{dB}$ since the radiation characteristic for both antennas are affected by lossy environment.

A reference value is estimated by placing IPF antenna with $3 \mathrm{~mm}$ inside the human hand model and the wearable antenna is in a free space environment which is at the top of the hand skin model as shown in Figure 2. The value of power ratio $\left|S_{21}\right|$ ref is verified. After that, a number of staggered distances of the antenna are computed starting from the hand skin surface up to $100 \mathrm{~mm}$. The reading of $\left|\mathbf{S}_{21}\right|$ air was recorded. The wave propagation of the antenna is unstable when the antenna is $500 \mathrm{~mm}$ away from the hand skin model due to the high losses. The rate of attenuation $\Delta$ (in $\mathrm{dB}$ ) can be calculated by $\left|\mathrm{S}_{21}\right| \mathrm{ref}-\left|\mathrm{S}_{21}\right|$ air. The attenuation per mm can also be obtained by considering $\Delta / d$, where $d$ is the distance from the surface of the hand skin model to the antenna in the air. Table 1 in Appendix section shows the results of antenna performances. 


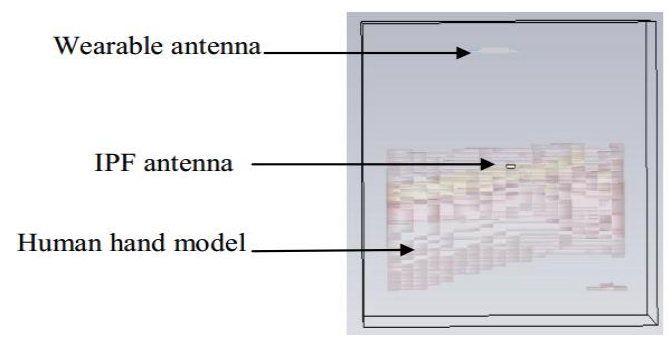

Figure 2. The antenna propagation setup in simulation

Table 1. Analysis of antennas performances for several distances

\begin{tabular}{cccccccc}
\hline $\begin{array}{c}\text { Distance } \\
(\mathrm{mm})\end{array}$ & $\mathrm{S}_{21}(\mathrm{~dB})$ & $\Delta(\mathrm{dB})$ & $\begin{array}{c}\Delta / \mathrm{mm} \\
(\mathrm{dB} / \mathrm{mm})\end{array}$ & Gain $_{1}(\mathrm{~dB})$ & $\operatorname{Gain}_{2}(\mathrm{~dB})$ & $\begin{array}{c}\text { Efficiency }_{1} \\
(\%)\end{array}$ & $\begin{array}{c}\text { Efficiency }_{2} \\
(\%)\end{array}$ \\
\hline 0 & -35.79 & & & -26.92 & 0.95 & 0.07 & 33.99 \\
10 & -39.98 & 4.19 & 0.419 & -29.09 & 4.74 & 0.05 \\
20 & -41.91 & 6.12 & 0.306 & -26.90 & 3.75 & 0.06 \\
30 & -43.45 & 7.66 & 0.255 & 25.63 & 3.38 & 0.08 & 67.59 \\
40 & -45.52 & 9.73 & 0.243 & -25.96 & 3.35 & 65.09 \\
50 & -48.08 & 12.29 & 0.245 & -26.14 & 3.58 & 0.08 \\
100 & -52.34 & 16.55 & 0.165 & -25.54 & 3.58 & 0.07 \\
\hline
\end{tabular}

where

Gain $_{1}=$ Gain of IPF antenna placed in the human hand voxel model.

Gain $_{2}=$ Gain of wearable antenna placed in free space environment.

Efficiency ${ }_{1}=$ Efficiency of IPF antenna placed in the human hand voxel model

Efficiency ${ }_{2}=$ Efficiency of wearable antenna placed in the free space enviromment

Table 1 illustrates some important data when both antennas are computed for several staggered distances. When the distance between both antennas is increased, the wave propagation loss is also increased. According to the Friss equation (1), as the total propagation loss is increased, the ratio of power transmitted and power received, S21 is also increased. The rate attenuation for the propagation is approximately $0.16 \mathrm{~dB}$ up to $0.42 \mathrm{~dB}$.

$$
\frac{\mathrm{Pr}}{\mathrm{Pt}}=G t+G r+\text { Total Propagation Loss }
$$

where:

$\mathrm{Pt}=$ Power transmitted $(\mathrm{dB})$

$\mathrm{Pr}=$ Power received $(\mathrm{dB})$

$\mathrm{Gt}=$ Gain transmitted $(\mathrm{dB})$

$\mathrm{Gr}=$ Gain received $(\mathrm{dB})$

According to the Table 1, the value of gain 1 is lower (reasonable for antenna in lossy environment) since the antenna is implanted in the human hand model while the value of gain 2 is higher due to the antenna is placed in the free space environment. The value of gain 2 is a necessity to be higher in order to create a reliable propagation link for in-body communication. Therefore, it can enhance the wave propagation from antenna inside the human hand model to the base station.

In terms of efficiency, the antenna efficiency for in the human hand model is maintained lower even though the distance between both antennas is increased. This factor is happening as the antenna location in the human hand model is not changed. There is only antenna in free space environment is moving away from the reference location. It can be observed that the antenna efficiency in a free space environment increases as the distance of the antenna is far away from the human hand model. This is because the tendency for signal to reflect or refract to human hand model is reduced.

\section{INVESTIGATION OF WAVE PROPAGATION IN TERM OF POLARZATION}

The main purposed of evaluating the antenna polarization is to determine the quality of wave propagation for several angles around the antenna implanted in the human hand model. The distance between both antennas is different depends on the angle of wearable antenna locations in free space environment. Figure 3 shows the 3-Dimension radiation pattern of antenna in the human voxel model. As illustrated in the 
figure, the maximum lobe of the radiation is directed to the upward from the body. There is no lobe at the back of the antenna structure because a human hand model acts as a reflector to the antenna. The polarization of wave propagation is analyzed in four different locations as shown in Figure 4.

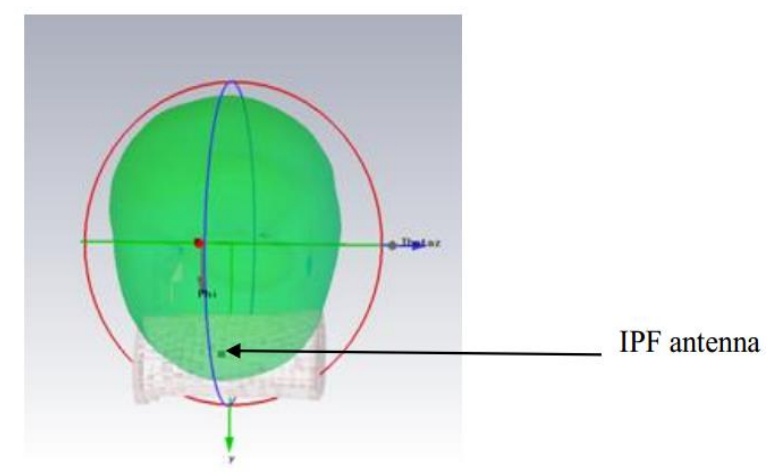

Figure 3. 3-Dimension radiation pattern of IPF antenna

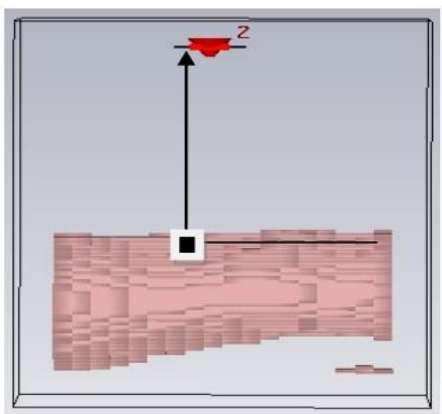

(a)

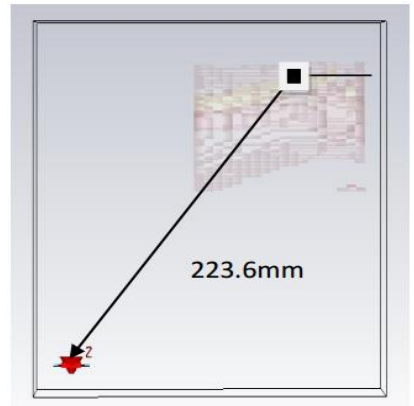

(d)

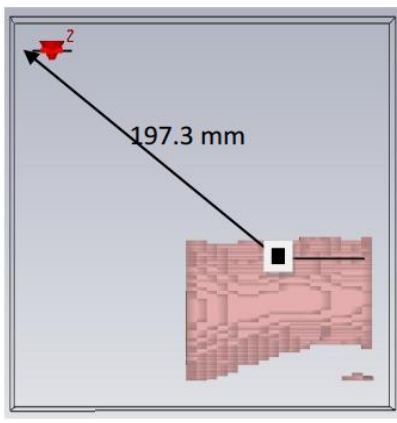

(b)

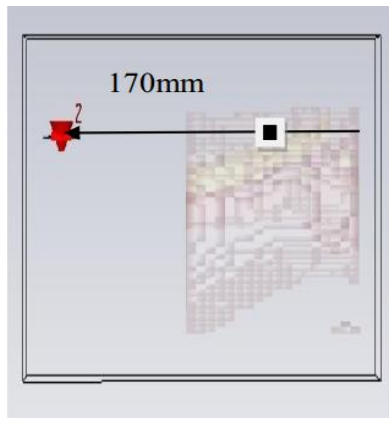

(c)

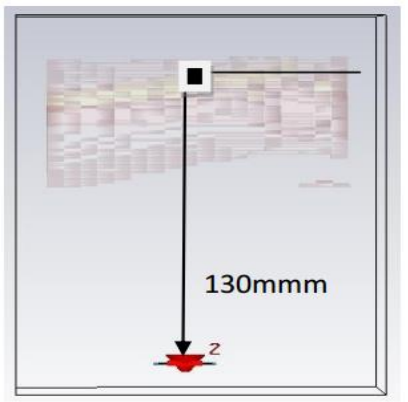

(e)

Figure 4. The angular rotation of antenna in free space environment (a) $90^{\circ}$ (b) $120^{\circ}$ (c) $180^{\circ}$ (d) $240^{\circ}$ (e) $270^{\circ}$

Table 2 tabulates several significant data of antenna wave polarization in term of $\mathrm{S}_{21}$, gain transmitted and receiver and antenna efficiency for transmitter and receiver. As illustrated in the table, the highest value of $S_{21}$ is obtained when both antennas are identical; each other with the distance between both antennas is $100 \mathrm{~mm}$. This feature may be happened as the wearable antenna is placed at maximum radiation of the IPF antenna as shown in Figure 3. It can be noticed that when wearable antenna is moved to angle $120^{\circ}$ and $180^{\circ}$ with distances between both antennas is $197.3 \mathrm{~mm}$ and $170 \mathrm{~mm}$, the value of $\mathrm{S}_{21}$ is decreased. This is because; the distance between both antennas is increased. Besides, the location of wearable antenna is in the minimum radiation region. Therefore the total of propagation loss is increased. The lowest value of $S_{21}$ is attained when wearable antenna, turn to $240^{\circ}$. Referring to the Figure 3, this location is outside of the radiation region. Due to the factor, the propagation link between both antennas is less stability. The propagation link of the antenna is also tested while wearable antenna is placed at the back of the human hand 
model. As expected, the link between both antennas is less stability, although the distance is $100 \mathrm{~mm}$ (similar distance when the wearable antenna is placed identically with IPF antenna). The main reason, contributes to the situation is the reflection and refraction of the antenna wave. The human hand model acts as a reflector therefore an antenna wave is reflected in the space.

Table 2. The performances of the antenna in five locations

\begin{tabular}{cccccc}
\hline Angle $\left(^{\circ}\right)$ & $\mathrm{S}_{21}(\mathrm{~dB})$ & Gain IPF $(\mathrm{dB})$ & Gain wearable $(\mathrm{dB})$ & Efficiency IPF $(\%)$ & Efficiency wearable $(\%)$ \\
\hline 90 & -52.34 & -25.54 & 2.581 & 0.07 & 71.34 \\
120 & -70.62 & -24.92 & 3.112 & 0.07 & 74.34 \\
180 & -79.32 & -24.45 & 2.717 & 0.08 & 72.79 \\
240 & -100.68 & -25.95 & 2.93 & 0.08 & 74.33 \\
270 & -74.43 & -25.04 & 4.43 & 0.08 & 73.82 \\
\hline
\end{tabular}

In term of gain, the value of gain in human hand model is lower, thus there are a necessity for wearable antenna to have higher gain to create a reliable wireless link for in-body communication. The efficiency of the antenna in the human hand model is maintained at the location of the antenna is not changed. While for wearable antenna in free space environment, the efficiency of the antenna increases as the distance between both antennas is increased. This is because the highest distances will reduce the tendency for the antenna wave to reflect or refract with the human hand model.

\section{CONCLUSION}

A wave antenna propagation simulation between antenna in free space and antenna implanted in the human hand voxel model is also presented in this chapter. The antenna wave propagation is evaluated in term of rate of attenuation and polarization. The rate attenuation for the propagation is approximately $0.16 \mathrm{~dB}$ up to $0.42 \mathrm{~dB}$. The main objective of estimating the antenna polarization is to verify the quality of wave propagation for several angles around the antenna implanted in the human hand model. The polarization of wave propagation is analysed in four different locations. Results show that the highest value of $S_{21}$ is obtained when both antenna are identical, each other with the distance between both antennas is $100 \mathrm{~mm}$. The lowest value of $S_{21}$ is attained when wearable antenna, turn to $240^{\circ}$ as this location is outside of the radiation region.

\section{ACKNOWLEDGEMENTS}

The authors wish to acknowledge the Short Term Grant (STG) provided by Universiti Malaysia Perlis (no. of project: 9001-00516) for funding this work. The members of Department of Electronic Engineering Technology, Faculty of Engineering Technology, UniMAP and Wireless Communication Centre (WCC), Faculty of Electrical Engineering, Universiti Teknologi Malaysia are also specially thanked for their helps and kindness.

\section{REFERENCES}

[1] P. S. Hall, et al., "Characterisation of Narrowband Communication Channels on the Human Body at 2.45GHz.IET Microw," Antennas Propag, vol. 4, pp. 722-732, 2010.

[2] K. Y. Yazdandoost, "A 2.4GHz Antenna for Medical Implanted Communications," AsiaPacific Microwave Conference, pp. 1775-1778, 2009.

[3] J. Abadia, et al., "3D-Spiral Small Antenna Design and Realization for Biomedical Telemetry in the MICS band," Radio Engineering, vol. 18, pp. 359-367, 2009.

[4] M. Kamarudin, et al., "Performance of antennas in the on-body environment," Antenna and Propagation Society International Symposium, pp. 475-478, 2005.

[5] K. Ito, et al., "Body effect on characteristics of small loop antenna in pager systems," Antenna and Propagation Society International Symposium, pp. 1081-1084, 1992.

[6] J. R. Panda , et al., "A Compact Printed Monopole Antenna for Dual-band RFID and WLAN Applications." Radio Enginnering, vol. 20, pp. 464-467, 2011.

[7] Y. Gao, et al., "Band-notched ultra-wideband ring-monopole antenna," Microwave and Optical Technology Letters, vol. 48, pp. 125-126, 2006 .

[8] N. H. Ramli, et al., "Investigation on a Compact Ring Printed Monopole Antenna for WiBAN Application Systems," Microwave and Optical Technology Letters, vol. 55, pp. 1053-1058, 2013.

[9] N. H. Ramli, et al., "A 6.0 GHz Chip Printed Monopole Antenna for Wireless Implantable Body Area Network (Wiban) Applications,” Progress in Electromagnetics Research C, vol. 41, pp. 189-200, 2013. 
[10] N. H. Ramli, et al., "A $4.8 \mathrm{GHz}$ implantable small printed antenna for wireless implantable body area network applications," IEEE International RF and Microwave Conference (RFM), 2013.

[11] N. H. Ramli and M. F. Ayob, "Design of a Chip Printed Antenna at $4.8 \mathrm{GHz}$ for Wireless Implantable Body Area Network Applications," Journal of Telecommunication, Electronic and Computer Engineering, vol. 10, 2018.

[12] N. H. Ramli, et al., "Numerical Investigation of a Chip Printed Antenna Performance for Wireless Implantable Body Area Network Applications," IOP Conference Series: Material Science and Engineering, vol. 318, 2018.

\section{BIOGRAPHIES OF AUTHORS}

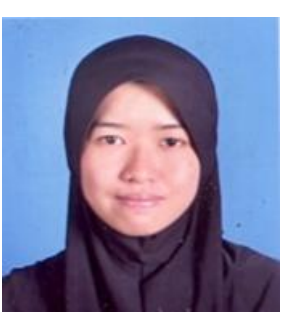

Nur Hidayah Ramli is a Senior Lecturer at the Department of Electronic Engineering Technology, Universiti Malaysia Perlis (UniMAP), Malaysia. She received her Ph.D in Electrical Engineering from Universiti Teknologi Malaysia. She is also a member of BEM and MBOT. Her research interests include antenna design and configuration, wireless sensor network, smart agriculture system and signal processing.

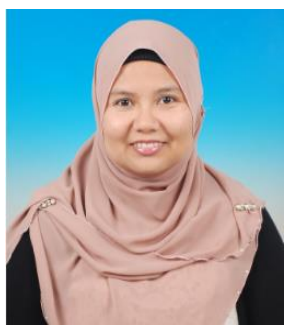

Haryati Jaafar is a senior lecturer in the Faculty of Engineering Technology at the Universiti Malaysia Perlis where she has been a faculty member since 2016. She received the M.Sc. degree and Ph.D. in Electrical and Electronic Engineering from the Universiti Putra Malaysia and Universiti Sains Malaysia, respectively. She is fellows of both the IEEE and MBOT. Her research topics include mathematical modeling, image processing and signal processing. She has collaborated actively with researchers in several other disciplines in biometric system, bioacoustics system and medical image analysis.

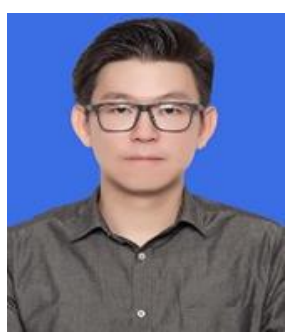

Lee Yeng Seng is a Senior Lecturer at the Department of Electronic Engineering Technology, Faculty of Engineering Technology, Universiti Malaysia Perlis (UniMAP), Malaysia. He received his Ph.D. in communication engineering from the School of Computer and Communication Engineering at Universiti Malaysia Perlis (UniMAP), Malaysia. He also a member of IET, BEM, IEEE Microwave Theory and Techniques Society. His research interests include dielectric material characterization, microwave absorber, Frequency Selective Surface (FSS), and antenna

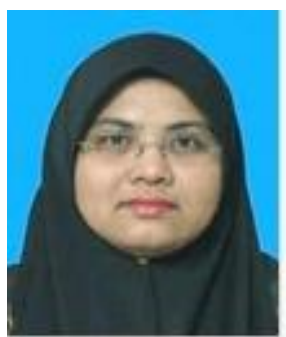

Hazila Othman is a Vocational Training at the Department of Electronic Engineering Technology, Universiti Malaysia Perlis (UniMAP), Malaysia. She received her Mcs in communication engineering from the School of Computer and Communication Engineering at Universiti Malaysia Perlis (UniMAP), Malaysia.. She is also a member of BEM and MBOT. Her research interests include antenna design and configuration, wireless sensor network, coupler and power divider. 